\title{
Hybrid heating systems optimization of residential environment to have thermal comfort conditions by numerical simulation
}

\author{
Nabi Jahantigh ${ }^{1 *}$, Ali Keshavarz ${ }^{2}$ and Masoud Mirzaei ${ }^{2}$
}

\begin{abstract}
The aim of this study is to determine optimum hybrid heating systems parameters, such as temperature, surface area of a radiant heater and vent area to have thermal comfort conditions. DOE, Factorial design method is used to determine the optimum values for input parameters. A 3D model of a virtual standing thermal manikin with real dimensions is considered in this study. Continuity, momentum, energy, species equations for turbulent flow and physiological equation for thermal comfort are numerically solved to study heat, moisture and flow field. $K-\varepsilon R N G$ Model is used for turbulence modeling and DO method is used for radiation effects. Numerical results have a good agreement with the experimental data reported in the literature. The effect of various combinations of inlet parameters on thermal comfort is considered. According to Pareto graph, some of these combinations that have significant effect on the thermal comfort require no more energy can be used as useful tools. A better symmetrical velocity distribution around the manikin is also presented in the hybrid system.
\end{abstract}

Keywords: Virtual manikin, Thermal comfort, Radiant panels, Optimal conditions, Conventional heating

\section{Introduction}

The convectional air conditioning equipment used for heating and cooling environment systems consume a lot of energy. Hybrid heating systems consist of two types of heating systems, namely radiation and convection. They work together to provide an efficient thermal comfort within an environment. This type of system can supply continuous heating energy even when one of them is off. Therefore, this technique is a very promising method which can reduce the energy consumption without lowering the level of comfort conditions.

In general, the thermal comfort is affected by the air temperature, mean radiant temperature; air velocity and relative humidity are included in the environmental parameters whereas the activity level and metabolic rate are categorized as the personal ones. Hence, in the hybrid system, the radiant heater temperature, surfaces, location, the air flow field, and metabolism are the most important factors affecting the level of thermal comfort in an environment [1].

\footnotetext{
* Correspondence: njahantigh@uoz.ac.ir

${ }^{1}$ Mechanical Engineering Department, University of Zabol, Zabol, Iran Full list of author information is available at the end of the article
}

So far, researchers have proposed different models to obtain higher level of thermal comfort in an environment $[2,3]$. Thermodynamic analysis of heat and mass of human body and its effects on thermal comfort were studied by Prek [4]. Jeet at el. [5] have evaluated the effect of high-temperature radiant heaters and windows on the thermal comfort. Despite Jeet's study, Myhern and Holmberg [6] have shown that low radiant panel temperature is more suitable for indoor environment. A combination of flow field around a human body was studied numerically by Murakumi, at el. [7]. A more complex model which includes the real body shape and physiology was considered by Kilic and Sevilgen [8]. They evaluated the heat transfer, mass, air flow and moisture around the human model.

As of now, the effects of flow and geometric parameters on thermal comfort have been studied in several papers individually. However, no detailed combinations of their interaction effects are seen in the literature. Therefore, in this study, the effects of input parameter such as temperature, surface area, and position of the radiant heaters along with their interactions on a hybrid heating system have been investigated. In addition, the 
Table 1 Range of input parameters

\begin{tabular}{lll}
\hline Effect Parameter & Min. & Max. \\
\hline Inlet area of the convection flow $(\mathrm{m})$ & 0.025 & 1 \\
Inlet flow velocity $(\mathrm{m} / \mathrm{s})$ & 0.05 & 1 \\
heater temperature $\left({ }^{\circ} \mathrm{C}\right)$ & 30 & 90 \\
The position of heater along vertical direction $(\mathrm{m})$ & 0.0 & 3 \\
The position of heater along Horizontal direction $(\mathrm{m})$ & 0.0 & 2 \\
The heater area $\left(\mathrm{m}^{2}\right)$ & 1 & 3.1 \\
\hline
\end{tabular}

air flow parameters of the convection system were also considered. The main objective of this study is to achieve thermal comfort in an indoor environment. In this simulation, a 3D model of a virtual standing thermal manikin with real dimensions is used. A numerical method was used to solve the flow field around the manikin. Also an optimization toward thermal comfort conditions is done.

\section{Governing equations and solutions}

The governing equations, consisting of continuity, momentum, energy, and mass transfer in a room which includes a manikin, are solved here. The radiation and turbulence equations are also considered in this problem. In addition, the Factorial Design Method (FDM) is used to analyze and optimize the variable effective parameters.

The conservation of mass can be written as [9]:

$$
\nabla \cdot(\rho \vec{V})=0
$$

The conservation of momentum is described by [10].

$$
\nabla \cdot(\rho \cdot \vec{V} \cdot \vec{V})=-\nabla p+\nabla \cdot(\overline{\bar{\tau}})+\rho \vec{g}
$$

The stress tensor $\bar{\tau}$ is given by;

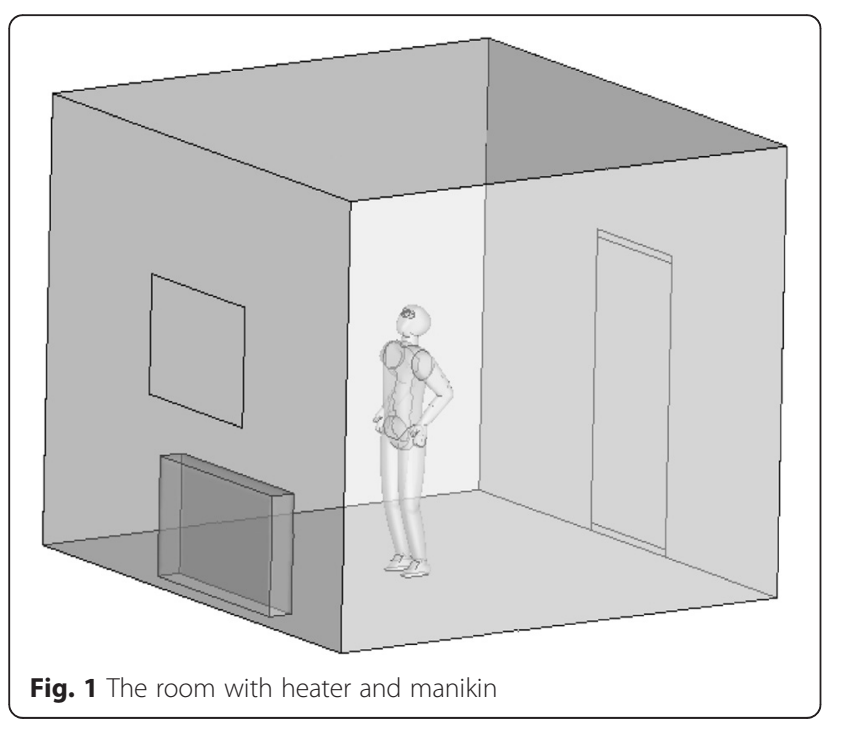

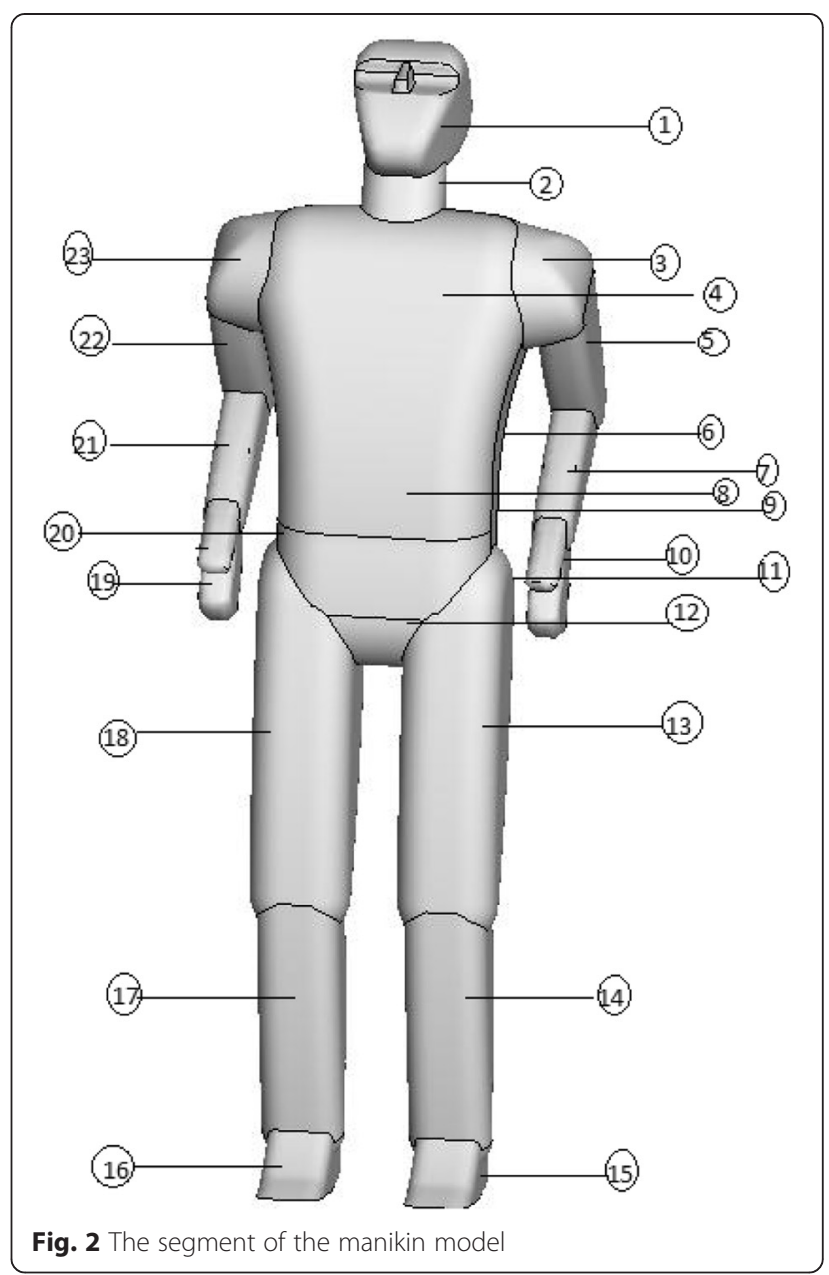

Table 2 Segment of the manikin and their area

\begin{tabular}{llc}
\hline Number & Surface Name & Surface Area $\left(\mathrm{m}^{2}\right)$ \\
\hline 1 & Head & 0.15898 \\
3,23 & Neck & 0.028926 \\
4 & Right \& Left shoulder & 0.048249 \\
5,22 & Brisket & 0.234812 \\
6,20 & Right \& Left arm & 0.098026 \\
7,21 & Right \& Left & 0.021141 \\
8 & Right \& Left forearm & 0.068715 \\
9 & Bowl & 0.038951 \\
10,19 & Waist & 0.210502 \\
11 & Right \& Left hand & 0.052163 \\
12 & Basin & 0.041288 \\
13,18 & Pelvis & 0.027313 \\
14,17 & Right \& Left tigh & 0.287548 \\
15,16 & Right \& Left leg & 0.160346 \\
\hline
\end{tabular}




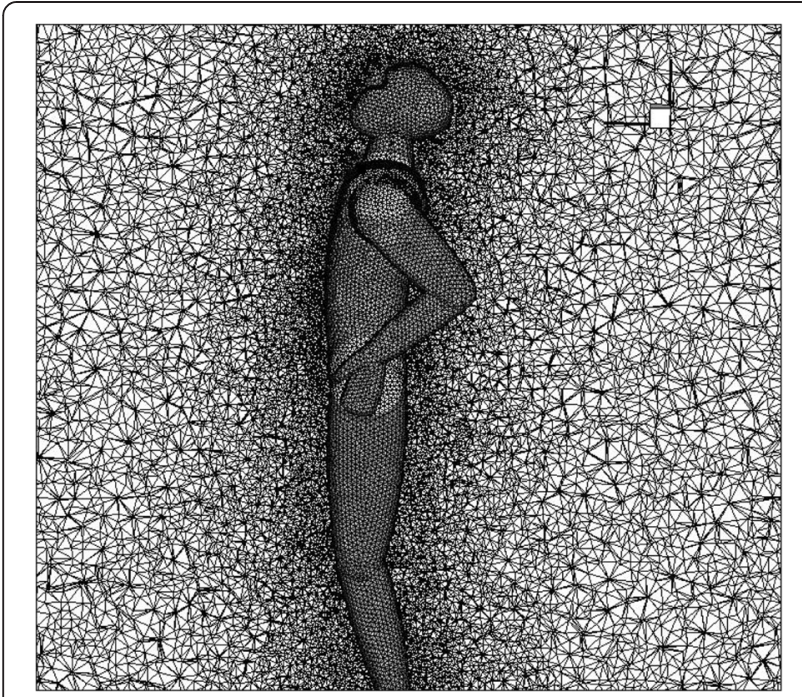

Fig. 3 The computational domain in the room

$$
\overline{\bar{\tau}}=\mu[(\nabla \vec{V}+\nabla \vec{V} T)]-\frac{2}{3} \nabla \cdot \vec{V} I
$$

The energy equation is:

$$
\nabla \cdot(\vec{V}(\rho E+p))=\nabla \cdot\left(k_{e f f} \nabla T-\sum_{j} h_{j} \vec{J}+(\overline{\bar{\tau}} \cdot \vec{V})\right)
$$

In Equation 4,

$$
E=h-\frac{p}{\rho}+\frac{V^{2}}{2}
$$

Where $h$ is defined as

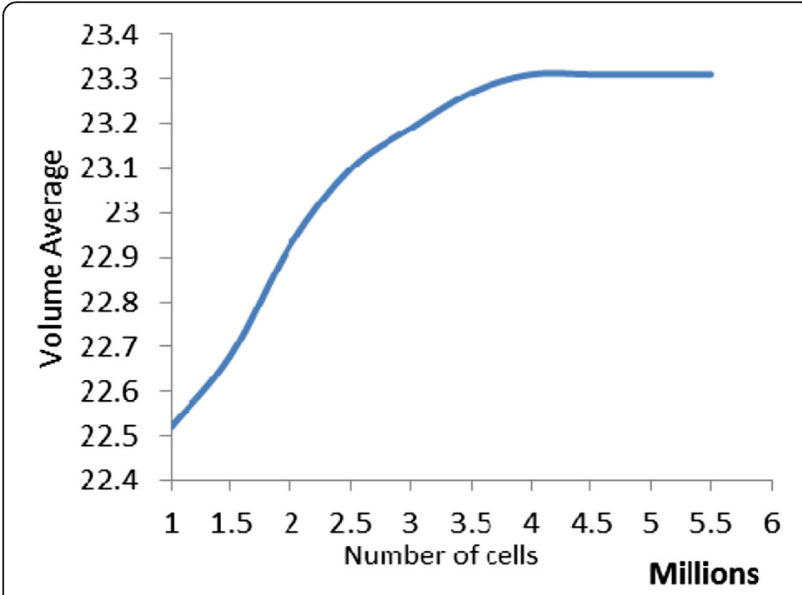

Fig. 4 The effects of the cell number on the volume-averaged

\begin{tabular}{|c|c|c|c|c|}
\hline zone & $\mathrm{T}{ }^{\circ} \mathrm{C}$ & type & $\mathrm{Vm} / \mathrm{s}$ & Mass flow \\
\hline inlet & 10 & velocity & 0.15 & $9.5 \mathrm{gH}_{2} \mathrm{O} / \mathrm{kgAir}$ \\
\hline Out let & & ssure outlet & & \\
\hline \multirow[t]{2}{*}{ body } & 33.1 & covered & & $10 \mathrm{gH}_{2} \mathrm{O} / \mathrm{kgAir}$ \\
\hline & 33.7 & uncovered & & \\
\hline wall & 25 & No slip & 0 & \\
\hline
\end{tabular}
temperature of room
Table 3 Boundary condition

$$
h=\sum_{j} Y_{j} h_{j}+\frac{p}{\rho}
$$

Where, $Y_{j}$ is the mass fraction of species $\mathbf{j}$ and

$$
h_{j}=\int_{T_{r e f}}^{T} C_{p, j} d T
$$

Here $T_{r e f}$ is $298.15 \mathrm{~K}$.

The conservation equation for the species transport in the general form is:

$$
\frac{\partial}{\partial t}\left(\rho Y_{j}\right)+\nabla \cdot\left(\vec{V} Y_{j}\right)=\nabla \cdot \vec{j}
$$

The mass diffusion $\vec{J}$ in turbulent flow is:

$$
\vec{j}=-\left(\rho D_{j, m}+\frac{\mu_{t}}{s c_{t}}\right) \nabla Y_{j}-D_{T, j} \frac{\nabla T}{T}
$$

Where, $S c_{t}$ is the turbulent Schmidt number.

The Predicted Mean Vote, PMV which is the response of large groups of people to the temperature sensitivity of an environment based on ASHRAE Standard is stated as the following equation [11].

$$
P M V=(0.303 \exp (-0.035 M)+0.028) L
$$

The heat balance equation of a human body is given as;

$$
S=M \mp W \mp R \mp C \mp K-E_{s k}-\left(C_{r e s}+E_{r e s}\right)
$$

By solving the flow field, all terms in equation 11can be calculated.

Table 4 Physical characteristic of material [15]

\begin{tabular}{llll}
\hline & Door & Wall & Window \\
\hline width & 50 & 250 & 25 \\
$\rho\left(\mathrm{kg} / \mathrm{m}^{3}\right)$ & 700 & 1940 & 840 \\
$C_{p}(\mathrm{kj} / \mathrm{kg} . K)$ & 2.31 & 0.84 & 0.84 \\
$K\left(\mathrm{~W} / \mathrm{m}^{2} . K\right)$ & 0.173 & 0.06 & 0.2 \\
$\varepsilon$ & 0.9 & 0.95 & 0.8 \\
\hline The emissivity coefficient value for the manikin has been considered as 0.98
\end{tabular}




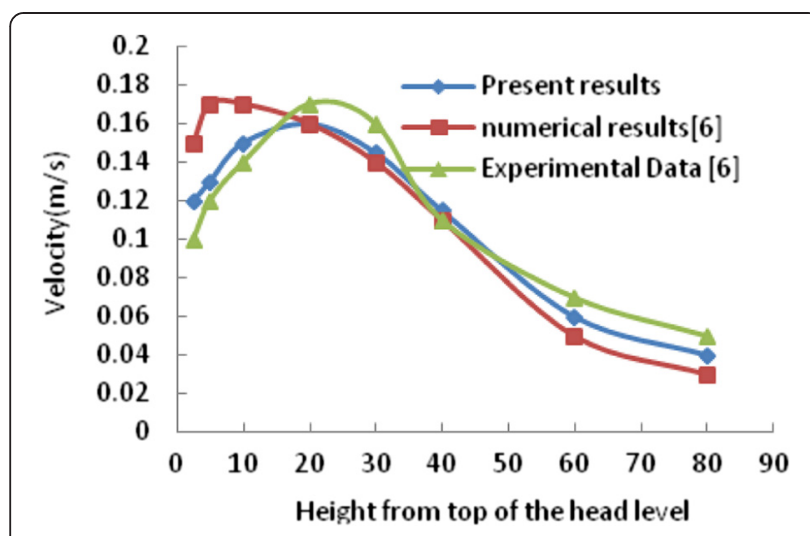

Fig. 5 Comparison the computed velocity with Numerical and experimental results of ref. [16]

When $S=0$, the thermal equilibrium will be satisfied [6]. In equation $11 E_{s k}, C_{\text {res }}$ and $E_{\text {res }}$ terms can be calculated as follows

$$
\begin{aligned}
& E_{s k}=\frac{w\left(P-P_{a}\right)}{R_{c l}} \\
& C_{r e s}=0.0014 M(34-T) \\
& E_{\text {res }}=1.72 \times 10^{-5} M\left(5867-P_{a}\right)
\end{aligned}
$$

The Factorial Design Method $\left(2^{k}\right)$ or two level design is used here for optimization [12]. The input and output parameters' range must also be specified. The input parameters are the area of convection flow, inlet flow rate, temperature, location, and the surface area of radiant heater. The output effective parameters are the radiation flux, convection flux, and PMV index. In this technique, the impact of the factor is defined as the difference between the high and low level of responses.

The values of input parameters based on some primary calculations are given in Table 1 . The critical and major effects of parameters are defined in Pareto and normal probability graphs. Their effects can also be stated as a regression equation. Then, the model is optimized for the objective function with the method of least squares and logistic regression [13].

A 3D computational code was used to solve the flow field, energy, and mass equation. The PISO algorithm has been used [14]. In this approach, higher-order accuracy is achieved at cell faces. Pressure discretization is done by second order method. The $K-\varepsilon R N G$ is also suitable for low-Reynolds numbers and more accurate and reliable for a wider range of indoor environments and flows with heat transfer.

The $D O$ radiation model is used to consider the radiation effects of heating surfaces and sources in the flow fluid simulation. It allows the solution of radiation at semi-transparent walls.

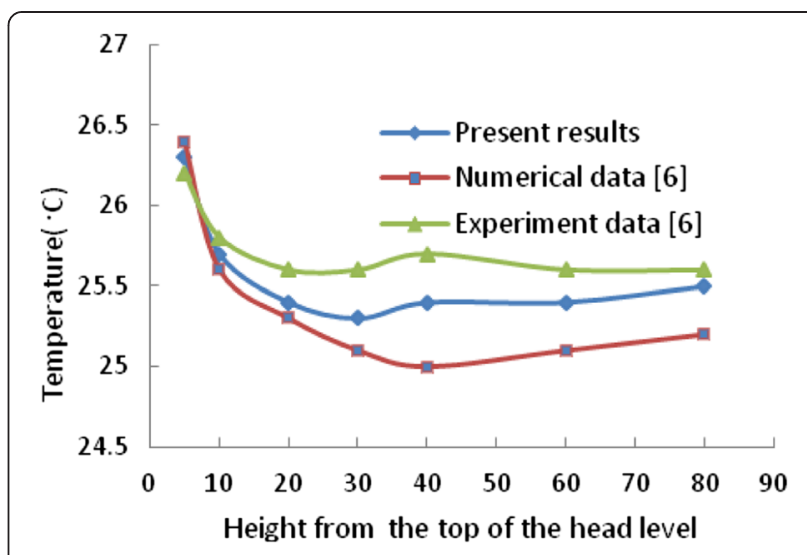

Fig. 6 Comparison the computed temperature with Numerical and experimental results of ref. [16]

\section{Geometry of the problem}

As be shown in Fig. 1 the problem consists of a manikin model stand and a radiant heater located within a room. One window, a door, and two vents at the bottom and top of the door have been considered for the circulation of air flow. Room dimensions are $3 \times 4 \times 4 \mathrm{~m}$. The manikin has a height of $1.75 \mathrm{~m}$ and weight of $75 \mathrm{~kg}$. The dimension of the window and door is $1 \times 1.2 \mathrm{~m}$ and $1 \times 2 \mathrm{~m}$, respectively. The size of the inlet, outlet and the heater are assumed to be variable for the optimization purpose.

The segments of the manikin model have been shown schematically in Fig. 2 and their values are tabulated in Table 2 .

This problem was first modeled using Solid Work and, then, meshed by Hypermesh software. The problem is solved for several different heater locations to optimize its position in the room.

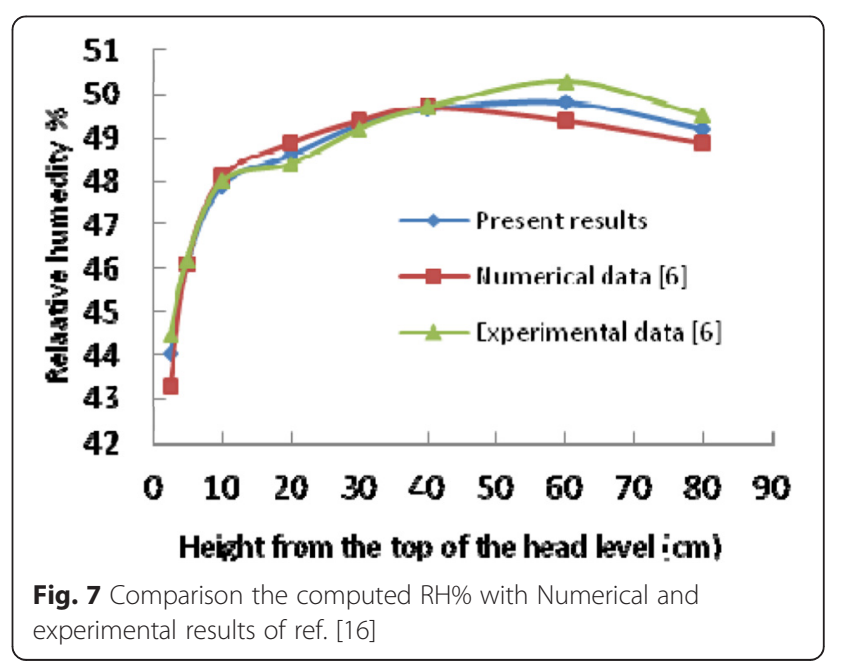




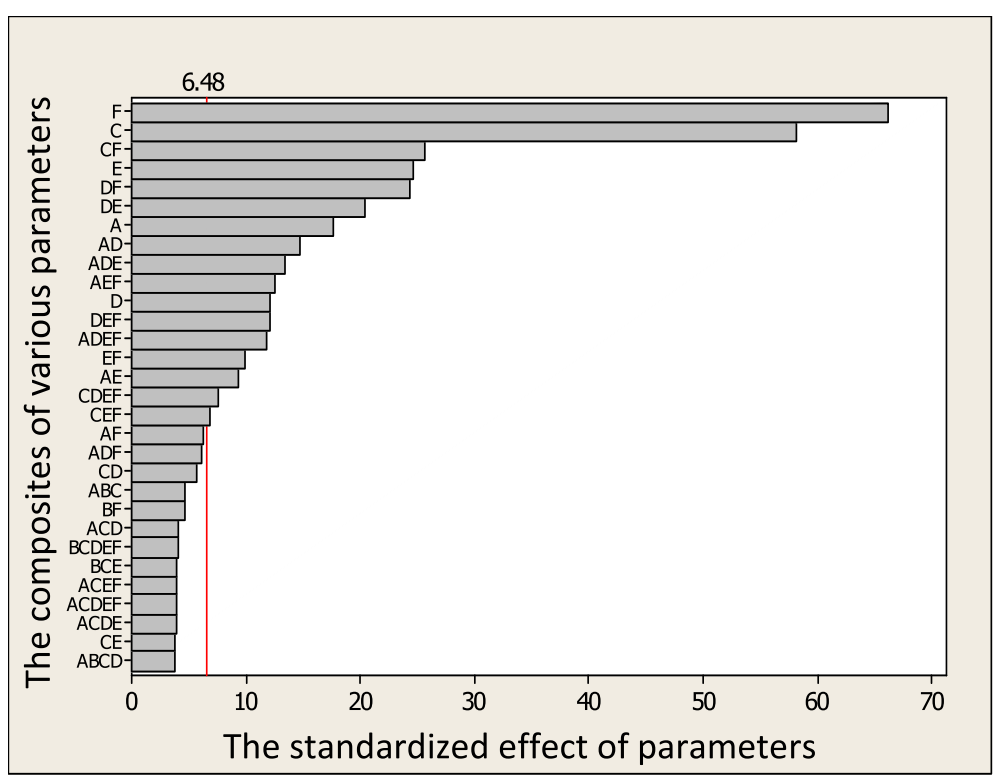

Fig. 8 The effect of the input parameter on the PMV index

\section{Computational grid}

Due to complex geometry and fine surfaces in this problem, generating structured grid for all sub regions is not an easy task. Therefore, a combination of unstructuredstructured grid system is applied using Algorithm T-Grid. It has been shown in Fig. 3. Since the flow field around the manikin includes high gradients of flow parameters, an appropriate distribution function starts from the lower layer around the surface and continues to the maximum step. The problem was solved for several different grid sizes for its independency. As shown in Fig. 4 the final results are independent numbers of grids when it is selected as 3,900,000 [15].

\section{Boundary conditions}

The boundary conditions are given in Table 3. These values are taken based on ASHRAE standard [15]. The characteristics of building materials are given in Table 4 .

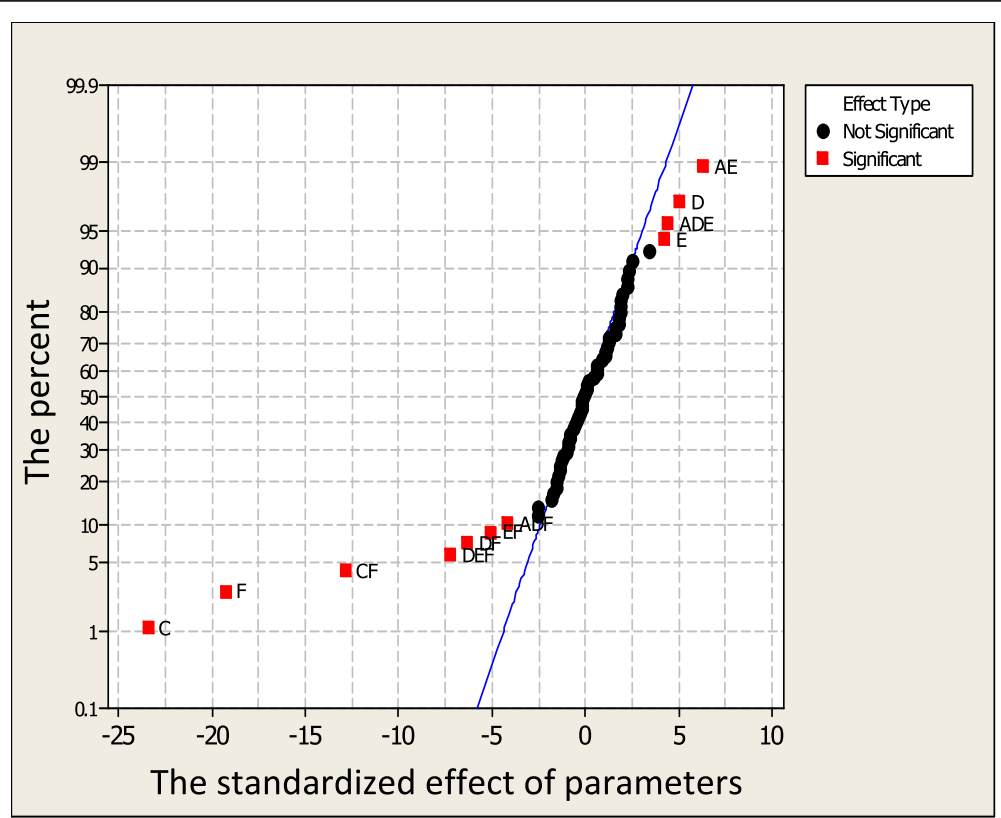

Fig. 9 The effect of the input parameter on the radiation flux 
Table 5 Optimized value for objective parameter

\begin{tabular}{llllllll}
\hline Input parameter & Min. & Max. & Suggested value & Optimized value & Objective parameter & $\begin{array}{r}\text { Target value } \\
\text { Computed value } \\
\text { along the target }\end{array}$ \\
\hline Inlet velocity $(\mathrm{m} / \mathrm{s})$ & 0.025 & 1 & 0.2 & 0.1 & PMV & 0.001 & -0.1 \\
Inlet area $\left(\mathrm{m}^{2}\right)$ & 0.05 & 1 & 0.4 & 0.12 & Total flux & 110 & 107.679 \\
Radiation heater temperature $\left({ }^{\circ} \mathrm{C}\right)$ & 30 & 90 & 45 & 30.034 & Radiation flux & 40 & 39.778 \\
The vertical position of heater $(\mathrm{m})$ & 0.0 & 3 & .1 & 0.2 & Relative humidity & 50. & 50.001 \\
The horizontal position of heater $(\mathrm{m})$ & 0.0 & 2 & 2 & 1.85 & & \\
The heater area $\left(\mathrm{m}^{2}\right)$ & 1.0 & 3.1 & 1.5 & 1.749 & &
\end{tabular}

Locating the heater opposite the person and under the window seems to be the best achievement for the above case. In this case, minimum heat losses are obtained while having optimum PMV value

\section{Validation of results}

For the validation of the present model, the calculated result was compared to the available experimental data in the literature [16]. The compression for the velocity, temperature and relative humidity are shown in Figs. 5, 6 and 7, respectively. As shown in these figures, the obtained values have a high agreement with the experimental data [16]. The maximum difference between the experimental and numerical velocity, temperature and relative humidity is $0.03 \mathrm{~m} / \mathrm{s}, \quad 0.4{ }^{\circ} \mathrm{C}$ and $0.5 \%$, respectively.

\section{Results and discussion}

The impact of input parameters on the objective functions

The effect of input parameters on the objective parameters using Pareto and normal charts are compared and discussed in Figs. 8 and 9 The Pareto chart presents the significant effect of the parameters whereas the normal chart indicates their percentage. The effect of input parameters on the total heat flux, PMV index, radiation heat flux, and relative humidity are shown in these Figures, respectively.

In these Figures, the letter $\mathrm{A}$ is the cross section area of the inlet vent, $\mathrm{B}$ is the input velocity, $\mathrm{C}$ is the heater temperature, $\mathrm{D}$ and $\mathrm{E}$ are the positions of heaters along the horizontal and vertical directions, and $\mathrm{F}$ is the surface area of the heater. The impacts of these parameters as well as their combinations are studied individually.

Hence, by glancing at all Figs. 8 and 9 it can be concluded that:F has the most effect on the object function and requires more energy $\mathrm{C}$ has the most effect on the objective function and needs no more energy. The combination of input parameters has different impacts on the objective function in comparison to their individual ones due to their interaction. Some of these combinations which can be used as useful tools have significant effect on thermal comfort and require no more energy

\section{The optimization}

The effect of input parameters on the objective parameters is determined in previous section and they are

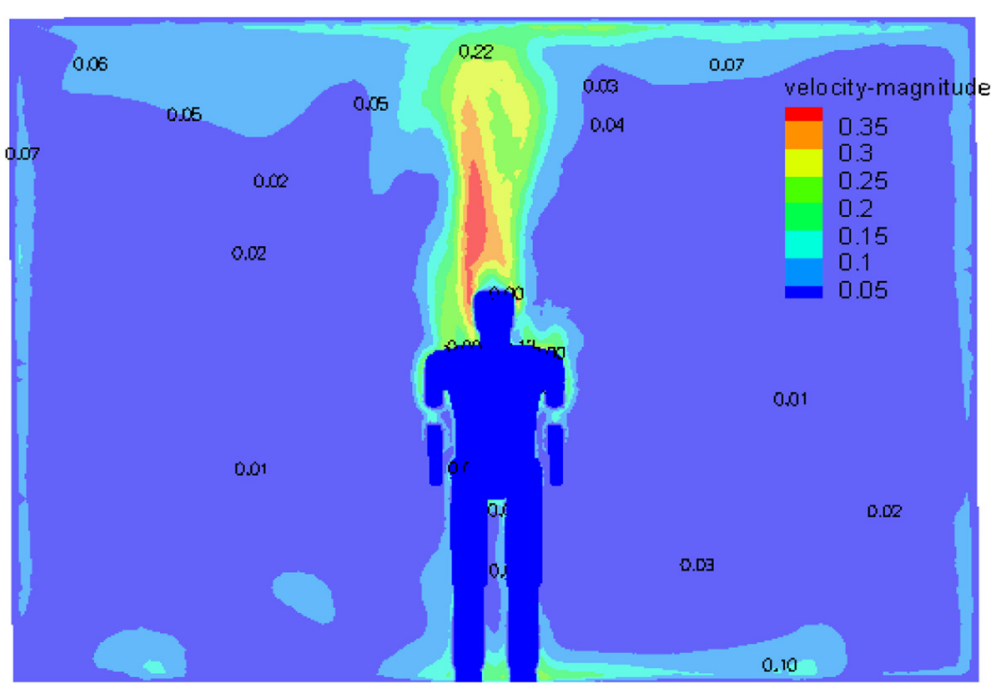

Fig. 10 The velocity contribution for optimum case 


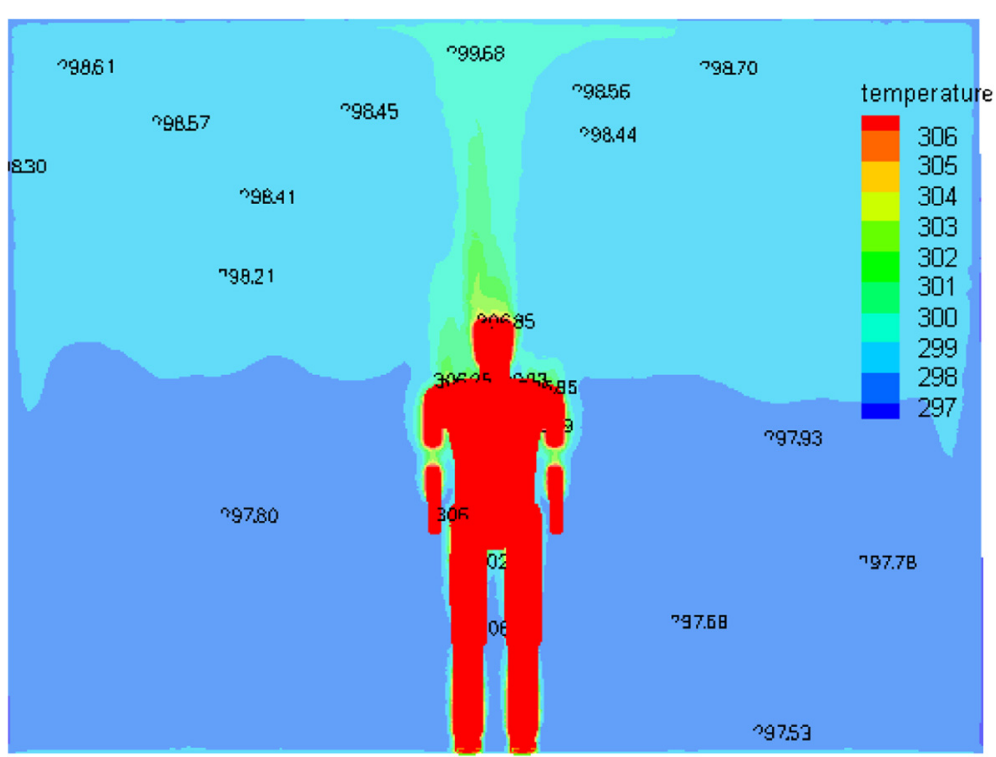

Fig. 11 The temperature contribution for optimum case

optimized here for different cases. In this case, the problem is optimized for the values of total flux $110 \mathrm{w} / \mathrm{m}^{2}$, radiation flux $40 \mathrm{w} / \mathrm{m}^{2}$, relative humidity $50 \%$ and PMV 0.001 . The optimized values are calculated and tabulated in Table 5.

\section{Velocity, temperature and relative humidity distribution around the manikin}

The Velocity, temperature, and humidity contours around the manikin surface are shown in Figs. 10, 11 and 12. A better symmetrical velocity distribution around the manikin is also presented in the hybrid system. The maximum velocity occurs near the head of the manikin due to larger temperature gradient. The all distribution values around the manikin are within the ASHRAE standard [15] and there is almost no stagnation zone which provides a proper thermal comfort for a person According to temperature contour in Fig. 11.

\section{Thermal comfort}

The fraction of convection and radiation heat flux in heating systems, convection and hybrid, for all segments of the manikin are tabulated in Table 6.

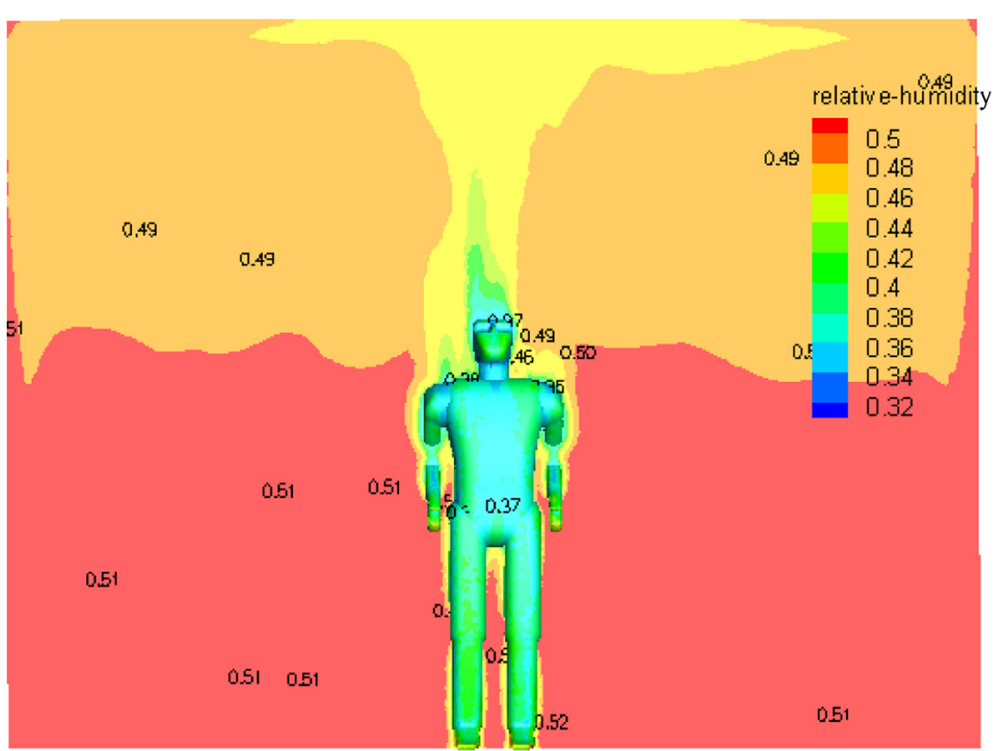

Fig. 12 The humidity contribution for optimum case 
Table 6 Heat losses rate from body

\begin{tabular}{lllll}
\hline Surface & Case-l & & Case- II & \\
& Con. Flux $\left(\mathrm{w} / \mathrm{m}^{2}\right)$ & Rad. Flux $\left(\mathrm{w} / \mathrm{m}^{2}\right)$ & 39.65 & 41.53 \\
\hline Head & 43.14 & 38.61 & 34.45 & 45.37 \\
Brisket & 35.82 & 37.44 & 31.92 & 46.03 \\
Bowl & 33.73 & 35.90 & 30.68 & 39.85 \\
Pelvis & 31.73 & 32.27 & 32.57 & 38.32 \\
Waist & 33.32 & 31.76 & 31.91 & 40.23 \\
Basin & 33.84 & 34.79 & 41.39 \\
Arm & 37.1 & 32.47 & 36.54 & 39.69 \\
Forearm & 38.35 & 30.66 & 37.61 & 54.28 \\
Shoulder & 35.27 & 38.71 & 34.29 & 48.37 \\
Thigh & 34.44 & 31.69 & 33.73 & 43.84 \\
Leg & 41.34 & 36.10 & 40.69 & 45.78 \\
Neck & 33.36 & 35.23 & 38.62 & 42.64 \\
foot & 46.81 & 34.69 & 45.31 & 38.69 \\
hand & 41.69 & 29.24 & 40.15 & 44.35 \\
Average & 37.1 & 33.7 & 35.68 & \\
\hline
\end{tabular}

Table 7 presents the heat losses from the body and walls, and PMV values for both heating systems. As the values of PMV indicate, the heating hybrid systems can provide faster and better human thermal comfort in a residential room. The PMV value for the convection heating systems is -0.86 whereas for the hybrid system, it is 0.0034 which is almost near the ideal condition $(\mathrm{PMV}=0)$ Despite the fact that the maximum velocity in this system is lower than the conventional heating system but it falls within the ASHRAE standard. This lower velocity makes lower heat losses through the walls and the manikin segments up to $25 \%$.

\section{Conclusion}

In this study, two heating systems, conventional and hybrid, are individually optimized and then compared with each other to have thermal comfort conditions. The

Table 7 Heat losses rate from body, room and PMV values in two cases

\begin{tabular}{lll}
\hline & Case 1 & Case 2 \\
\hline T air & 24.5 & 25.52 \\
TMRT & 24.03 & 25.23 \\
Relative humidity & 55.36 & 50.46 \\
Convection flux & 36.68 & 32.86 \\
Radiation flux & 33.61 & 45.23 \\
losses & 35.27 & 22.21 \\
Total flux of the body & 105.56 & 100.3 \\
PMV & -0.89 & 0.0034 \\
Total flux of the room & 684.61 & 512.83 \\
\hline
\end{tabular}

Factorial Design Method $\left(2^{\mathrm{K}}\right)$ or two level designs has been used for optimization. The effect of input parameters and their interaction is investigated on the objective function, such as PMV index, relative humidity and heat fluxes. The effects of the input parameters in normal and Pareto charts are presented. Based on the present study, the individual and the interaction of input parameters effect are significant and different. Heater temperature has the most effect on the object function and requires more energy whereas $C$ has the most effect on the objective function but needs no more energy thus some combination can be used as useful tools in designing heating systems. The thermal comfort can be obtained using less input energy by just increasing the surface area of the heater and its location. A better symmetrical velocity distribution around the manikin is also presented in the hybrid system. The lower velocity makes lower heat losses through the walls and the manikin segments up to $25 \%$. The heating hybrid systems can provide faster and better human thermal comfort in a residential room.

\section{Thanksgiving}

I would like to thank all those who have helped me in doing the research. Also, I want to thank you for giving us the opportunity to publish our paper in the Journal of Environmental Health Science and Engineering.

\section{Nomenclature}

$C$, Convective heat loss $(\mathrm{w} / \mathrm{m} 2)$

$C_{\text {res }}$, Convection heat loss due to respiration $(\mathrm{w} / \mathrm{m} 2)$

$D_{i, m}$, Mass diffusion coefficient for species

$D_{T}$, Turbulent diffusivity 
$E_{\text {res }}$, Evaporative heat loss due to respiration(w/m2)

$E$, Total energy (J)

$E_{s k}$, Evaporative heat loss of skin

$\vec{g}$, Gravitational acceleration

$h$, Sensible enthalpy

$I$, Unit tensor

$\vec{j}$, Diffusion flux of species

$k_{\text {eff }}$, Effective conductivity

$k_{t}$, Turbulent thermal conductivity

$L$, The heat load of the body

$M$, Metabolic heat production $\left(\mathrm{w} / \mathrm{m}^{2}\right)$

$P_{\alpha}$, ambient pressure air (kpa)

$P M W$, Predict mean vote

$R_{c l}$, Resistance of clothes

$R$, Radiative heat $\operatorname{loss}\left(\mathrm{w} / \mathrm{m}^{2}\right)$

$S$, Heat storage $\left(\mathrm{w} \backslash \mathrm{m}^{2}\right)$

$\vec{V}$, Velocity vector

$W$, External work $\left(\mathrm{w} / \mathrm{m}^{2}\right)$

$Y_{j}$, Mass fraction of species

$\mu$, Molecular viscosity

$\rho$, Density

$\overline{\bar{\tau}}$, Stress tensor

\section{Competing interests}

The authors declare that they have no competing interests.

\section{Authors' contribution}

All authors read and approved the final manuscript

\section{Author details}

${ }^{1}$ Mechanical Engineering Department, University of Zabol, Zabol, Iran.

${ }^{2}$ Mechanical Engineering Department, K. N. Toosi University of Technology,

Tehran, Iran.

Received: 29 May 2013 Accepted: 11 May 2015

Published online: 31 May 2015

\section{References}

1. Bemani M., "Modern air conditioning practice", 3rd ed., ISBN-964-8142-31-9, Ketab Iran Publication.

2. Orosa JA. Research on general thermal comfort models. Eur J Sci Res. 2009;27(2):217-27. 1450-216X

3. Van Hoof J, Hansen JLM. Quantifying the relevance of adaptive thermal comfort models in moderate thermal climate zones. Build Environ. 2007;42:156-70.

4. Prek M. Thermodynamic analysis of human heat and mass transfer and their impact on thermal comfort. Int J Heat Mass Transfer. 2005;48:731-9.

5. Jeet S, Chapman K.S., Keshavarz A. "Window performance for human thermal comfort". 4765(RP) 1126.

6. Myhern JA, Holmberg S. Flow: "Pattern and thermal comfort in a room with panel floor and wall heating". Energy and Building. 2008;40:524-6.

7. Muarkumi S, Zeng J, Hayashi T. "CFD analysis of wind environment around a human body". J Wind Eng Ind Aero. 1999;83:393-408.

8. Kilic M, Sevilgen G. "Modeling airflow, heat transfer and moisture transport around a standing human body by computational fluid dynamics". Int Communication in Heat and Mass transfer. 2008;35:1159-64.

9. White FM. "Viscous Fluid Flow", 2nd ed. omide enghelab publication, c2006.

10. Batchelor GK. "An Introduction to Fluid Dynamics". Cambridge, England: Cambridge Univ. Press; 1967.

11. Wyon DP, Fanger PO, Olesen BW, Pedersen CJK. "The mental performance of subjects clothed for comfort at two different air temperatures". Ergonomics. 1975;18:358-74.
12. Montgomery C. "Design and analysis of experiments". Douglas - 5th ed. ISBN 0-471-31649-0.

13. Jiju A. "Design of Experiments for Engineers and Scientists", ISBN: 0750647094 Publisher: Elsevier Science \& Technology Books, Pub. Date: October; 2003.

14. Barth TJ, Jespersen D. "The design and application of upwind schemes on unstructured meshes". Reno, Nevada: Technical Report. AIAA -89-0366. AIAA 27th Aerospace Sciences Meeting; 1989.

15. ASHRAE. Hand Book-Fundamental Refrigeration and Air-Conditioning Engineers, Atlanta: American Society of Heating; 2001 (chapter 8).

16. Kilic M, Sevilgen G. Numerical analysis of air flow, heat transfer, moisture transport and thermal comfort in a room heated by two-panel radiators. Energy and Buildings. 2011;43:137-46.

\section{Submit your next manuscript to BioMed Central and take full advantage of:}

- Convenient online submission

- Thorough peer review

- No space constraints or color figure charges

- Immediate publication on acceptance

- Inclusion in PubMed, CAS, Scopus and Google Scholar

- Research which is freely available for redistribution 